\title{
Special issue: Supply chain network design in emerging markets
}

\author{
Rosa G. González-Ramírez ${ }^{1}$ • Igor Litvinchev ${ }^{2}$
}

Accepted: 17 March 2016 / Published online: 20 May 2016

(C) Springer Science+Business Media New York 2016

Network design determines the physical configuration of a supply chain in terms of number, location and size of different facilities such as plants and depots or warehouses, as well as the assignment of customers or retailers to plants or warehouses.

Compared to developed countries emerging markets face more complex problems since there are additional factors to consider and challenges to overcome related to the limited Information Technology infrastructure, legal and regulatory conditions, customer segmentation, transport infrastructure, capabilities, geographical and environmental conditions, as well as social and political issues that add more complexity to the traditional decision problems arising in supply chain network design. This special issue considers supply chain networks in their full generality, reflecting supply chain networks in their general sense.

The International Congress on Logistics \& Supply Chain (CILOG) provides for researchers and practitioners in the field of logistics and supply chain management an opportunity to present their current research and results in a warming and fruitful environment. The CILOG is one of the leading events in Latin America and the Caribbean in the area of logistics and supply chain management and provides a platform for sharing knowledge and promotes collaboration among participants from the academia, private and public sectors.

This volume of the Journal NETNOMICS consists of contributions covering recent advances and emerging computational paradigms in designing and evaluating supply chain networks in emerging countries. The special issue is based on revised

Rosa G. González-Ramírez rgonzalez@uandes.cl

1 Faculty of Engineering and Applied Science, Universidad de Los Andes, Chile, Santiago, Chile

2 Nuevo Leon State University, Monterrey, Mexico 
and extended presentations of the CILOG 2014 that was held in Mexico City at the University Anahuac, during October $15^{\text {th }}$ to $17^{\text {th }}, 2014$.

The CILOG 2014 was the second of its kind, the first was held in Sanfandila, Queretaro, Mexico at the facilities of the Mexican Institute of Transport in 2013, and the third one was held also in Sanfandila, Queretaro, Mexico in 2015. The fourth one is planned to be held in Merida, Mexico in October 2016.

During the CILOG 2014 conference, a total of 51 papers were presented. For this volume, a total of 15 papers were submitted from which four papers were selected for publication. The contributions presented at the conference as well as this selected group of papers show the importance of logistics and supply chain network decisions, both in academia and in practice, with an emphasis on those applications in Latin American and Caribbean countries.

In the paper "A framework for strategy formulation in sustainable supply chains: a case study in the electric industry" Maria D. Gracia and Luis E. Quezada present a new methodological approach to support the strategies formulation process in sustainable supply chain. The capability and usefulness of the proposed methodology are shown through a case study in the Mexican Federal Commission of Electricity Gulf-Center Distribution Division. The company is large and complex enough to encompass the whole issue of the supply chain and results obtained indicate that the proposed approach is a valid decision support tool.

In the paper "Reducing the carbon footprint in a vehicle routing problem by pooling resources from different companies" Manuel Sanchez, Lorena Pradenas, Jean-Christophe Deschamps and Victor Parada propose a mathematical formulation for the vehicle routing problem with time windows, considering the carbon footprint as a constraint, supported by the hypothesis that pooling resources may reduce both the carbon footprint and economic costs. The model is solved by a scatter search metaheuristic and analyzed from the perspective of game theory to evaluate the stability of the coalition after pooling.

In the paper "Multi-product capacitated facility location problem with general production and building costs" Alejandro Montoya, Mario C. Vélez-Gallego and Juan G. Villegas extend the classical facility location problem by including multiple products and general production and building cost functions that allow modelling of different behaviours like economies of scale and congestion. The problem is formulated as a mixed integer linear program solved by commercial software or by a randomized mathematical programming based heuristic.

In the paper "Solid waste management in Mexico's offshore platform construction: determining potential supply for a reverse logistics process" Zahira Gabriela Cruz Netro, Juana Elizabeth Medina Álvarez, Araceli Cartas Carrillo and Rodolfo Garza Flores present an analytical, statistical and historical study that focuses on the management of municipal solid waste and special handling waste, specifically, the one generated in the construction of offshore platforms in Mexico. A comparative analysis of the waste generated domestically and in the construction of offshore platforms is done.

March 2016

Rosa G. González-Ramírez Igor Litvinchev 